\title{
Classification of WSN Routing Protocol Based On Clustering
}

\author{
C. Sudha ${ }^{1}$, D. Suresh ${ }^{2}$ and A. Nagesh ${ }^{3}$ \\ ${ }^{1}$ Research Scholar, ${ }^{2}$ Assistant Professor, ${ }^{3}$ Professor \\ ${ }^{1 \& 2}$ Department of Information Technology, Annamalai University, Chidambaram, Tamil Nadu, India \\ ${ }^{3}$ Department of Computer Science Engineering, Mahatma Gandhi Institute of Technology, Hyderabad, India \\ E-Mail: csudhahyd@gmail.com, deiveekasuresh@gmail.com, akknagesh@rediffmail.com
}

\begin{abstract}
Wireless Sensor Networks (WSNs) within the zone time regulate to greater enticing and develop their manner into massive variance of exercise in distinctive domains. Elevation in wireless sensor network technology provide the affability of small and low cost sensor nodes with the adequacy of sensing, processing, computing the physical and surroundings circumstances. Due to inhibition in transmission range, processing and power resources it is considered necessary to design awesome and energy aware protocol to increase network lifetime. Routing strategies are developing to boom life cycle of sensor network and increase throughput performance. This paper gives, an analysis of various routing strategies used in wireless sensor networks in addition importance of cluster based routing, and varieties of cluster, type of cluster based routing are discussed. The observe concludes with the issues and the resent researchers on cluster based routing.
\end{abstract}

Keywords: WSN, Sensor Nodes, Cluster Based Routing

\section{INTRODUCTION}

Now a day's wireless sensor networks are generally used in civilian application areas which include monitoring, tracking, health application, traffic control. WSN consist of wireless modules known as sensor nodes [1]. Due to hindrance on transmission bandwidth, power supply and processing functionality, efficient routing becomes important in wireless sensor network. According to the structure of network routing in WSN is divided into two types: flat routing and hierarchical routing. In flat routing, all of the node perform the same task and feature equal capability in network. Generally Flooding approaches are used wherein data dissemination is finished hop by hop. It is handiest in small-scale networks [2].

They come to be undesirable for the large scale networks because of limited resources and more requirements of bandwidth and data processing. In hierarchical routing all node have to execute unique tasks and they in most cases grouped into clusters on the basics of requirements. [3] It is task of making grouping set of item in group that should be much like one another and special from the items in different groups. Clustering is beneficial while similarity and distinction between the groups are more. Grouped cluster have nodes with one-of-a-kind energies in which higher energy nodes are consider as the cluster heads and that they carry out the task of data processing and data dissemination, at the same time as nodes with lower energy acts as member nodes and perform data sensing. [4] Each node of the cluster directly communicate with cluster head, then cluster head ahead the sensed data to Base station (BS). Cluster heads can communicate with each different within the network or directly to base station. Clustering algorithm has kind of advantages which include scalability, less load, less energy consumption and more strong. Clustering of nodes minimizes residual energy and maximize network overall performance. [6] This improves the overall network traffic and decreases network lifetime.

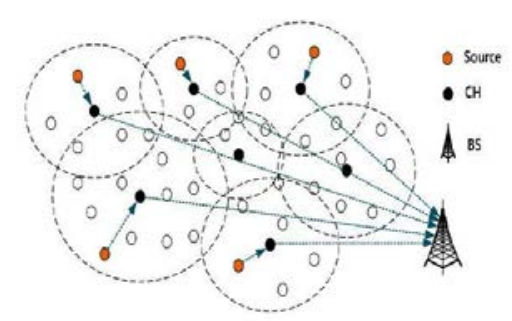

Fig. 1 clustering process in WSN

\section{RELATED WORK}

TABLE I LITERATURE SURVEY ON CLUSTERING APPROACHES IN THE PAST FEW YEARS.

\begin{tabular}{|c|c|c|}
\hline Year & Author & Contribution \\
\hline 2006 & Arboleda.et al. [7] & Analysis of LEACH based Protocol \\
\hline 2007 & Abbasi et al.[ 8 ] & $\begin{array}{l}\text { Comparison of popular clustering } \\
\text { methods }\end{array}$ \\
\hline 2008 & $\begin{array}{l}\text { Kumarawadu et } \\
\text { al.[9] }\end{array}$ & $\begin{array}{c}\text { Discussion of the key design } \\
\text { challenges of WSN Clustering }\end{array}$ \\
\hline 2009 & Jiang et al.[10] & $\begin{array}{c}\text { Analysis of popular WSN clustering } \\
\text { algorithm }\end{array}$ \\
\hline 2010 & Maimour et al.[11] & $\begin{array}{c}\text { WSN clustering protocols based on pre } \\
\text { established and on demand basis. }\end{array}$ \\
\hline 2011 & Wei et al.[12] & Challenges in WSN clustering \\
\hline 2013 & $\begin{array}{l}\text { Gulbadan Sikander } \\
\text { et al.[13] }\end{array}$ & $\begin{array}{l}\text { Classification of Cluster-based Routing } \\
\text { Schemes in WSNs }\end{array}$ \\
\hline 2014 & $\begin{array}{l}\text { Santar Pal Singh et } \\
\text { al.[14] }\end{array}$ & $\begin{array}{c}\text { Issues in cluster based routing } \\
\text { techniques }\end{array}$ \\
\hline 2016 & $\begin{array}{l}\text { Shreshtha Misra et } \\
\text { al.[15 ] }\end{array}$ & Clustering classification \\
\hline 2017 & $\begin{array}{l}\text { Varchika Gupta et } \\
\text { al.[16] }\end{array}$ & $\begin{array}{c}\text { Cluster Based Routing Protocols In } \\
\text { Wsn }\end{array}$ \\
\hline
\end{tabular}

\section{CLUSTER BASED ROUTING PROTOCOL IN WSN}

When efficient communication and network scalability is needed cluster routing is considered as energy efficient 
approach. In which better energy nodes are performs processing and sending data even as lower energy nodes are used for sensing and sending data to cluster heads (CHs). Cluster based routing protocols are categorized as block cluster based, grid cluster based and chain cluster based routing.

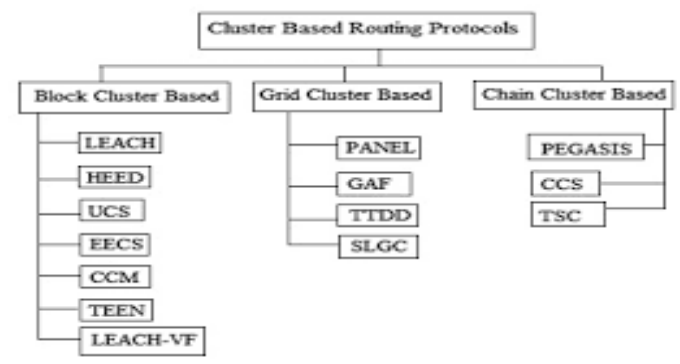

Fig. 2 Cluster based Routing protocol

A. Block Cluster Based Protocol: It is the efficient method for clustering used for the real-time detection.

1. Low-Energy Adaptive Clustering Hierarchy (LEACH): The main intention of LEACH is to choose sensor nodes as cluster heads by means of rotation, so that high energy dissipation in communicating with the base station is spread to all sensor nodes in the network. The nodes arrange themselves into local clusters, in which one node acts because the local base station or cluster head. LEACH also plays local data compression, reducing the amount of data sent from the clusters to the base station, which further reduces energy dissipation and complements system lifetime.

2. Hybrid Energy-Efficient distributed (HEED): The essential intention of HEED is to prolong network existence. The fundamental difference among HEED and LEACH is cluster head election; cluster head election in HEED is not random. The production of clusters is primarily based on residual energy of the node and intracluster communication cost. Cluster heads have higher average residual energy than the member nodes. The communication technique of HEED is the same as LEACH.

3. UCS Unequal Clustering Size (UCS): Clusters of same length may cause an unbalanced load on the cluster heads, but an unequal size of clusters can offer more balanced energy consumption for cluster heads.

4. Energy Efficient Clustering Scheme (EECS): In this the nodes which have extra residual energy is elected because the cluster head. [13]. Across the network the range of cluster is uniform and divide the network into clusters and it uses direct verbal exchange between the cluster head and base station.

5. Threshold-sensitive Energy Efficient sensor Network (TEEN): It's essential use is in time-critical programs. TEEN is an aggregate hierarchical and data-centric approach

6. Chain-Cluster-based Mixed (CCM): CCM is a routing set of rules that organizes the sensor nodes as a fixed of horizontal chains and a vertical cluster with best chain heads.

7. LEACH with Virtual Force (LEACH-VF): The concepts of virtual discipline force on every cluster in the network so that it will circulate the sensor nodes to places that maximize the sensing coverage and minimize the transmitted energy.

TABle Ii Review Under Block Cluster Based Routing Protocols

\begin{tabular}{|c|c|c|c|}
\hline Protocol & Proposed by & Merits & Limitation \\
\hline LEACH & Heinzelman & $\begin{array}{l}\text { As load is shared between the node and each node } \\
\text { have equal chance to become cluster head in the } \\
\text { subsequent round. } \\
\text { To prevent congestion TDMA is used } \\
\text { Between the cluster head selection. }\end{array}$ & $\begin{array}{l}\text { Single hop communication takes place so LEACH } \\
\text { cannot be used for large scale networks. } \\
\text { It cannot provide the load balancing and cluster head } \\
\text { are elected on basics of probability due to } \\
\text { which uniform distribution cannot achieved }\end{array}$ \\
\hline HEED & $\begin{array}{l}\text { Younis and } \\
\text { Fahmy }\end{array}$ & $\begin{array}{l}\text { Fully distributed cluster based routing. } \\
\text { Achieves load balancing and uniform } \mathrm{CH} \\
\text { distribution. } \\
\text { High energy efficiency and scalable due to multi hop } \\
\text { communication. }\end{array}$ & $\begin{array}{l}\text { Unbalance energy consumption due to more number } \\
\text { of clusters. } \\
\text { Massive overhead due to multiple rounds. } \\
\text { Several iterations are done to form cluster leads to } \\
\text { additional overhead }\end{array}$ \\
\hline UCS & Soro et al., & $\begin{array}{l}\text { To maintain uniform energy consumption, the } \\
\text { number of nodes varies. Low energy consumption as } \\
\text { compared to LEACH. }\end{array}$ & $\begin{array}{l}\text { Cluster heads are predetermined as well as network is } \\
\text { not homogeneous. It is not suitable for large range } \\
\text { network as residual energy is not considered. }\end{array}$ \\
\hline EECS & Ye et al., & $\begin{array}{l}\text { Energy consumption and communication are balance } \\
\text { in the network. Large distance communication with } \\
\text { base station requires lot of energy for this dynamic } \\
\text { sizing of clusters are used. }\end{array}$ & $\begin{array}{l}\text { Congestion due to global information for } \\
\text { communication. Lot of energy consume due to single } \\
\text { hop communication. }\end{array}$ \\
\hline TEEN & $\begin{array}{l}\text { Anjeshwar } \\
\text { et al., }\end{array}$ & $\begin{array}{l}\text { Transmissions of data are controlled by two } \\
\text { threshold values. Mostly prefer for the time-critical } \\
\text { applications. }\end{array}$ & $\begin{array}{l}\text { When the values of the threshold are different, node } \\
\text { will not able to communicate. If node will not able to } \\
\text { communicate then data may be lost. }\end{array}$ \\
\hline CCM & Tang et al., & $\begin{array}{l}\text { less energy consumption } \\
\text { less delay }\end{array}$ & Chain head selection criterion \\
\hline $\begin{array}{l}\text { LEACH- } \\
\text { VF }\end{array}$ & Awad et al., & $\begin{array}{l}\text { Solve the problem of area with overlapped sensing } \\
\text { coverage and sensing hole } \\
\text { In LEACH-VF some nodes can be moved to } \\
\text { coverage inside the cluster }\end{array}$ & $\begin{array}{l}\text { Poor energy efficiency } \\
\text { Load balancing is not up to the mark }\end{array}$ \\
\hline
\end{tabular}


B. Grid Cluster Based Routing Algorithms: The records space is quantized into limited wide variety of cells within the form of grid and all of the clustering operation is completed on grid.

1. Geographic Adaptive Fidelity (GAF): Is an energy-aware routing algorithm designed mainly for mobile hoc networks however that may be relevant to WSNs as properly. GAF is a location- based routing algorithm, but it is able to additionally be taken into consideration a clustering algorithm in which the clusters are based totally on geographic region.

2. The Position-based Aggregator Node Election scheme (PANEL): It is a position-based totally routing scheme for WSNs. PANEL isn't the same as other ANEL schemes because it supports asynchronous sensor network applications. To pick any node as an aggregator, PANEL uses the placement records of the node.
3. The Two-Tier Data Dissemination (TTDD): This approach enables to resolve the couple of mobile sink problem. TTDD bureaucracy a grid structure and makes use of the sensor nodes on the grid points for data transmission. So rather than waiting passively for the sink to send records queries, it proactively builds a grid structure with the sensors closest to the grid point.

4. Hierarchical Geographic Multicast Routing (HGMR): It is a location- based multicast scheme. The primary concept of HGMR is cell geographic hashing. Inside each group, HGMR makes use of Geographic Multicast Routing (GMR) to ahead data alongside the multicast tree.

5. SLGC: Clustering algorithm that organizes the network into grids, sending data by way of the cluster head in every cluster, for this reason increasing network lifetime and reducing energy intake. In SLGC, the data of every cluster is sent to the bottom station using a single-approach SLGC algorithm.

Table Ii Summarizes The Merits And Limitations Of Grid Cluster Based Routing Protocols

\begin{tabular}{|c|l|l|l|}
\hline Protocol & Proposed by & \multicolumn{1}{|c|}{ Mertics } & \multicolumn{1}{c|}{ Limitation } \\
\hline PANEL & $\begin{array}{c}\text { Buttyan and } \\
\text { Schaffer }\end{array}$ & $\begin{array}{l}\text { PANEL is an energy-efficient scheme that } \\
\text { ensures load balancing and a long network } \\
\text { lifetime because each node becomes a cluster } \\
\text { head with equal probability. } \\
\text { It supports asynchronous applications. }\end{array}$ & $\begin{array}{l}\text { In PANEL, clusters are predetermined, } \\
\text { which makes it inapplicable to WSNs. }\end{array}$ \\
\hline TTDD & Luo et al., & $\begin{array}{l}\text { Resolves the multiple-mobile sinks and sink- } \\
\text { moving problem in large-scale WSNs }\end{array}$ & $\begin{array}{l}\text { Suited to event-detecting WSNs with } \\
\text { irregular, rather than continuous, data } \\
\text { traffic }\end{array}$ \\
\hline HGMR & $\begin{array}{c}\text { Koutsonikolas } \\
\text { et al., }\end{array}$ & $\begin{array}{l}\text { Does not face the scalability problem because } \\
\text { only manageable Destinations exist in a cell. } \\
\text { energy-efficient }\end{array}$ & $\begin{array}{l}\text { The simple network partition may not } \\
\text { achieve the optimal routing paths. }\end{array}$ \\
\hline SLGC & $\begin{array}{c}\text { Xu } \text { et al., } \\
\text { active and sleep periods and at least one node is } \\
\text { active in a cell. Hence, routing fidelity is } \\
\text { maintained. (GAF can increase the lifetime of the } \\
\text { network by saving energy. }\end{array}$ & $\begin{array}{l}\text { GAF may result in large traffic injection, } \\
\text { and the delay is not predictable and } \\
\text { bounded. This makes it unsuitable for real- } \\
\text { time scenarios in WSNs }\end{array}$ \\
\hline $\begin{array}{l}\text { Higher efficiency level for network lifetime } \\
\text { compared to LEACH lower energy consumption } \\
\text { than LEACH. }\end{array}$ & $\begin{array}{l}\text { Large overhead due to complex data } \\
\text { communication }\end{array}$ \\
\hline
\end{tabular}

\section{C.Chain Cluster Based Routing Algorithms}

1. Power-Efficient Gathering in Sensor Information Systems (PEGASIS): The primary idea behind PEGASIS is that every node communicates most effective with its near neighbours and will become the leader for transmission to the sink, one at a time. The nodes are randomly located, and every sensor node has abilities for facts detection, wireless communication, data fusion, and positioning. Energy load is evenly allotted amongst all of the sensor nodes within the network.

2. The Concentric Clustering Scheme (CCS): The major idea of CCS is to think about the base station area to increase the life of the network and to enhance overall performance.
TABle IV Review Under Chain Cluster Based Routing Protocols

\begin{tabular}{|c|c|c|c|}
\hline Protocol & $\begin{array}{l}\text { Proposed } \\
\text { by }\end{array}$ & Merits & Limitation \\
\hline PEGASIS & $\begin{array}{l}\text { Lindey } \\
\text { et al., }\end{array}$ & $\begin{array}{l}\text { Energy load is } \\
\text { distributed } \\
\text { uniformly Reduce } \\
\text { overhead due to } \\
\text { dynamic cluster } \\
\text { formation } \\
\text { Decrease number of } \\
\text { data transmission }\end{array}$ & $\begin{array}{l}\text { Long delays cause } \\
\text { a node to become } \\
\text { bottleneck } \\
\text { Network is not } \\
\text { very scalable } \\
\text { Not suitable for } \\
\text { time varying } \\
\text { topologies }\end{array}$ \\
\hline CCS & $\begin{array}{l}\text { Jung } \\
\text { et al., }\end{array}$ & $\begin{array}{l}\text { Energy consumption } \\
\text { is reduced } \\
\text { Reduced data flow } \\
\text { from BS in CCS }\end{array}$ & $\begin{array}{l}\text { Unbalanced energy } \\
\text { consumption } \\
\text { Large delay due to } \\
\text { long chain }\end{array}$ \\
\hline TSC & $\begin{array}{l}\text { Gautam } \\
\text { et al., }\end{array}$ & $\begin{array}{l}\text { TSC reduces } \\
\text { redundant data } \\
\text { transmission in } \\
\text { network by breaking } \\
\text { long chains into } \\
\text { smaller chains }\end{array}$ & $\begin{array}{l}\text { Node distribution } \\
\text { in unbalanced }\end{array}$ \\
\hline
\end{tabular}


3. Track-Sector Clustering (TSC): The network is partitioned into concentric round tracks and triangular sectors. The division of tracks and sectors saves energy because it minimizes redundant data transmission and offers the shortest distance among cluster head and base station. A cluster in TSC is a place under a curved strip fashioned by the intersection of a circular track and a triangular track.

\section{RESEARCH AREAS IN CLUSTER-BASED WSNS}

Cluster-based schemes recently proposed lot of critical concern for the deployment of wireless sensor network [16]. Still there are some latest researches issues in cluster-based WSNs are as follows:

A. Cluster Head Selection: It is based on the parameters such as number of $\mathrm{CHs}$, round number, time interval, node ID, and location information.

The issues it faces are as follows

1. Sheer probabilistic.

2. Network resources and parameters are not considered.

3. Sensor nodes have to periodically update latest information.

4. Imposes extra overhead to heavy-loaded CHs.

B. Cluster Formation: It is based event location and direction of data flow also minimizes the energy expenditure in clustering. The issues it faces are as follows

1. Extra overhead in terms of communication and process on the regions that does not have event to report.

2. Nodes have to periodically transmit their sensor reading to BS.

C. Data Aggregation: Based on the optimum selection of aggregation efficiency, optimal cluster radius to achieve most efficient data aggregation. The issues it faces are as follows:

1. It increases the memory storage and delay time.

D. Data Communication: It is based on the long distance communication of CHs and BS, uses CDMA slots to avoid radio interference. Select optimum number of relay nodes. The issues it faces are as follows:

1. Extra overload to heavy loaded $\mathrm{CHs}$ that depletes the closeness of CHs to BS.

2. Communication between $\mathrm{CH}-\mathrm{CH}$ might be long distance transmission for large scale networks.

\section{CONCLUSION}

The existing routing strategies in wireless sensor network and its corresponding routing protocols had been explained.
Clustering based routing algorithm is best technique to reduce energy consumption and also provide stability and scalability in the network. We discuss the merits and limitations of cluster-based routing protocols in WSN. This paper will very useful for research group those are interested in development, modification or optimization of routing algorithms for WSNs.

\section{REFERENCES}

[1] F. Akyildiz, W. Su, Y. Sankarasubramaniam, and E. Cayirci, "A Survey on Sensor Netowrks," IEEE Communications Magazine, Vol.40, No.8, pp. 102-114, Aug 2002.

[2] Al-Karaki, and J.N. Kamal, "A.E. Routing techniques in wireless sensor networks: A survey”. IEEE Wireless Communication., 11, 628, 2004.

[3] P. Ding, J. Holliday, and A. Celik, "Distributed Energy Efficient Hierarchical Clustering for Wireless Sensor Networks". In Proceedings of the 8th IEEE International Conference on Distributed Computing in Sensor Systems (DCOSS), Marina Del Rey, CA, USA, 8-10; pp. 322- 339, June 2005.

[4] J. Yick, M. Biswanath, and D. Ghosal "Wireless Sensor Network Survey” Computer Networks, Vol.52, No.12, pp.2292-2330, 2008.

[5] W.B Heinzelman, A.P. Chandrakasan, and H.Balakrishnan, "Application specific protocol architecture for wireless micro sensor" April 2003.

[6] S. Bandyopadhyay and E.J Coyle,” An Energy Efficient Hierarchical Clustering Alogrithm for Wireless Sensor Networks", IEEE INFOCOM, April 2003.

[7] L.M.C. Arboleda and N. Nasser, "Comparison of clustering algorithms and protocols for wireless sensor networks," In Proceeding IEEE.

[8] A.A. Abbasi and M. Younis, "A survey on clustering algorithms for wireless sensor networks," Computing Communication, Vol. 30, Nos.14-15, pp. 2826-2841, Oct. 2007.

[9] P. Kumarawadu, D.J. Dechene, M. Luccini, and A. Sauer, "Algorithms for node clustering in wireless sensor networks: A survey," In Proceeding 4th International Conference Information Automation Sustainability, Colombo, Sri Lanka, pp. 295-300, Dec. 2008.

[10] C. Jiang, D. Yuan, and Y. Zhao, "Towards clustering algorithms in wireless sensor networks: A survey,” In Proceeding IEEE Wireless Communication Network Conference, Budapest, Hungary, pp. 1-6, April 2009.

[11] M. Maimour, H. Zeghilet, and F. Lepage, "Cluster-Based Routing Protocols for Energy-Efficiency in Wireless Sensor Networks,” Dec. 2010.

[12] C. Wei, J. Yang, Y. Gao, and Z. Zhang, "Cluster-Based Routing Protocols in Wireless Sensor Networks: A Survey" In Proceedings of 2011 International Conference on Computer Science and Network Technology, Harbin, China, 24-26; pp. 1659-1663, Dec. 2011.

[13] Gulbadan sikandar "A survey of cluster based routing scheme for wireless sensor networks" smart computing review , Vol.3, No.4, August 2013.

[14] Santar Pal singh "cluster based routing algorithms for wireless sensor networks" IJETI, Vol.1 No.4, November 2014

[15] Shreshtha Misra "A Literature survey on various clustering approaches in WSN” IEEE CCIS 2016.

[16] Varchika Gupta "Survey on classification of clustering technique" IJARCCE, Vol. 6, No.4, April 2017. 